\title{
Mortality Associated with Metformin Versus Sulfonylurea Initiation: A Cohort Study of Veterans with Diabetes and Chronic Kidney Disease
}

\author{
Zachary A. Marcum, PharmD, PhD' , Christopher W. Forsberg, MS ${ }^{2}$, Kathryn P. Moore, PhD², \\ lan H. de Boer, MD, MS 3,4,5, Nicholas L. Smith, PhD 2,4,6,7, Edward J. Boyko, MD, MPH 2,3,8, and \\ James S. Floyd, MD, MS $3,4,6,7$
}

\begin{abstract}
'Department of Pharmacy, School of Pharmacy, University of Washington, Seattle, WA, USA; ${ }^{2}$ Seattle Epidemiologic Research and Information Center, VA Puget Sound Health Care System, Seattle, WA, USA; ${ }^{3}$ Department of Medicine, University of Washington, Seattle, WA, USA; ${ }^{4}$ Department of Epidemiology, University of Washington, Seattle, WA, USA; ${ }^{5}$ Kidney Research Institute, University of Washington, Seattle, WA, USA; ${ }^{6} \mathrm{Cardiovascular}$ Health Research Unit, University of Washington, Seattle, WA, USA; ${ }^{7}$ Kaiser Permanente Washington Health Research Institute, Kaiser Permanente Washington, Seattle, WA, USA; ${ }^{8}$ General Medicine Service, VA Puget Sound Health Care System, Seattle, WA, USA.
\end{abstract}

BACKGROUND: For patients with type 2 diabetes and chronic kidney disease (CKD), high-quality evidence about the relative benefits and harms of oral glucoselowering drugs is limited.

OBJECTIVE: To evaluate whether mortality risk differs after the initiation of monotherapy with either metformin or a sulfonylurea in Veterans with type 2 diabetes and CKD.

DESIGN: Observational, national cohort study in the Veterans Health Administration (VHA).

PARTICIPANTS: Veterans who received care from the VHA for at least 1 year prior to initiating monotherapy treatment for type 2 diabetes with either metformin or a sulfonylurea between 2004 and 2009.

MAIN MEASURES: Metformin and sulfonylurea use was assessed from VHA electronic pharmacy records. The CKD-EPI equation was used to estimate glomerular filtration rate (eGFR). The outcome of death from January 1, 2004, through December 31, 2009, was assessed from VHAVital Status files.

KEY RESULTS: Among 175,296 new users of metformin or a sulfonylurea monotherapy, 5121 deaths were observed. In primary analyses adjusted for all measured potential confounding factors, metformin monotherapy was associated with a lower mortality hazard ratio (HR) compared with sulfonylurea monotherapy across all ranges of eGFR evaluated (HR ranging from 0.59 to 0.80). A secondary analysis of mortality risk differences favored metformin across all eGFR ranges; the greatest risk difference was observed in the eGFR category 30$44 \mathrm{~mL} / \mathrm{min} / 1.73 \mathrm{~m}^{2}$ (12.1 fewer deaths/1000 personyears, 95\% CI 5.2-19.0).

CONCLUSIONS: Initiation of metformin versus a sulfonylurea among individuals with type 2 diabetes and CKD was associated with a substantial reduction in mortality, in terms of both relative and absolute risk reduction. The largest absolute risk reduction was observed among individuals with moderately-severely reduced eGFR (30$44 \mathrm{~mL} / \mathrm{min} / 1.73 \mathrm{~m}^{2}$ ).

Received July 21, 2017

Revised September 22, 2017

Accepted October 25, 2017

Published online November 27, 2017
KEY WORDS: diabetes; chronic kidney disease; mortality. J Gen Intern Med 33(2):155-65

DOI: $10.1007 / \mathrm{s} 11606-017-4219-3$

(c) Society of General Internal Medicine 2017

\section{INTRODUCTION}

Metformin, along with diet and exercise, is the first-line glucose-lowering treatment for patients with type 2 diabetes. ${ }^{1}$ At the time of its approval by the Food and Drug Administration (FDA) in 1995, metformin carried a contraindication based on serum creatinine levels due to fears about lactic acidosis caused by an older biguanide drug, phenformin. ${ }^{2}$ This contraindication led to avoidance of metformin use in many patients with renal insufficiency. ${ }^{3}$ In April 2016, the FDA changed the measure of kidney function used to determine whether patients could receive metformin, from a serum creatinine-based approach to one based on the estimated glomerular filtration rate (eGFR), which provides a more accurate assessment of renal function (Appendix Figure 3). ${ }^{4}$ The FDA concluded that metformin could be used safely in patients with mild impairment in kidney function and in some patients with moderate impairment.

Given this expanded eligibility for metformin therapy, and given the increasing burden of chronic kidney disease (CKD) in patients with diabetes, ${ }^{5}$ evidence is needed regarding the relative benefits and harms of metformin therapy in this population. While no randomized controlled trials have addressed this question, observational studies have examined metformin use and health outcomes in CKD populations. ${ }^{6-11}$ A recent systematic review identified major limitations in the design of these prior studies, including a lack of a well-defined comparator group to metformin, an assessment of medication use at baseline rather than during follow-up, and the inclusion of prevalent users rather than new users of diabetes therapies. $^{12}$

In an observational cohort of Veterans with type 2 diabetes and $\mathrm{CKD}$ who received regular healthcare from the Veterans Health Administration (VHA), we evaluated whether mortality risk differed after the initiation of monotherapy with either 
metformin or a sulfonylurea, the second most commonly prescribed class of oral glucose-lowering drugs after metformin. ${ }^{13}$ We sought to address some of the key limitations of prior studies. This analysis was conducted using data from 2003 to 2009 , a period of clinical equipoise regarding the choice of metformin or sulfonylureas when initiating treatment for type 2 diabetes. ${ }^{14}$

\section{METHODS}

\section{Setting and Data Sources}

The VHA uses a uniform national electronic medical record that captures information from all instances of medical care delivered in its facilities and prescriptions filled in its pharmacies. Demographic, comorbidity, laboratory, and medication use data from January 1, 2003, to December 31, 2009, were obtained from the VHA national medical and pharmacy data housed at the Austin Information Technology Center. Race/ ethnicity was determined from administrative data, which was based on self-report. The presence of comorbidities at baseline was identified using International Classification of Diseases, Ninth Revision (ICD-9) codes from outpatient encounters at VHA facilities that occurred within the year before initiation of diabetes therapy (Appendix Table 4). In a previous validation study, we found that ICD-9 code-based algorithms had moderate to good accuracy for identifying cardiovascular conditions and cardiovascular risk factors. ${ }^{15}$ For laboratory tests, only the most recent values within the year before initiation of diabetes therapy were used. Prescription records included drug name, quantity, number of days dispensed, and fill date. Weight was calculated as the median value of all measures obtained during the year in which the oral hypoglycemic medication was initiated, while height was taken as the median of all values. Body mass index (BMI) was calculated as weight $(\mathrm{kg}) /$ height $(\mathrm{m})^{2}$. The VA Puget Sound Health Care System Institutional Review Board reviewed and approved this research.

\section{Study Participants and Eligibility Criteria}

This was a new-user, national cohort study of Veterans with type 2 diabetes and CKD who received healthcare from the VHA and initiated monotherapy with either metformin or a sulfonylurea. A previous study reported on the comparative safety of glucose-lowering drugs among persons in this cohort without CKD, using similar methods. ${ }^{16}$ Veterans enrolled in the VHA who received at least two consecutive prescriptions for metformin or a sulfonylurea within a period of 180 days, between January 1, 2003 and December 31, 2009, were eligible for this analysis. Follow-up of patients began on the date of the second prescription. This time frame was chosen because, during that period, a state of clinical equipoise existed regarding initiation of treatment for type 2 diabetes with either metformin or sulfonylureas (Appendix Table 5). The
CKD-EPI Equation was used to estimate GFR, and individuals were classified according to eGFR categories. ${ }^{17,} 18$

To capture only new users of metformin or a sulfonylurea, we excluded Veterans who used any glucoselowering drugs (including insulin) before their first prescription for metformin or a sulfonylurea during the time period of interest. We also excluded Veterans who did not have prescriptions for non-diabetes medications obtained from VHA during the year before the first prescription for metformin or a sulfonylurea, because for these individuals we could not distinguish whether they were new users of oral diabetes therapies or prevalent users who had filled previous prescriptions for diabetes medications outside the VHA. To restrict our analysis to a population likely to be receiving care and medications from the VHA, we also excluded persons who did not have an outpatient visit to a VHA facility in the year before the first prescription for metformin or a sulfonylurea. In addition, we excluded patients with missing values for baseline serum creatinine and race, both of which are needed to estimate eGFR. Lastly, those with an eGFR of $<30 \mathrm{~mL} / \mathrm{min} / 1.73 \mathrm{~m}^{2}$ were excluded due to the small sample size.

\section{Assessment of Medication Use}

Individuals were categorized as initiators of metformin or a sulfonylurea at the time of cohort entry based on VHA prescriptions dispensed. The period of exposure for a given prescription started on the date the medication was dispensed and lasted for a period of time equal to 1.25 times the days' supply, plus 90 days. ${ }^{16}$ During follow-up, if another prescription for the same medication was not filled by the end of this period, it was assumed that the medication was discontinued at the end of the exposure period. Use of diabetes treatments other than metformin and sulfonylureas was captured to identify a change in treatment to another monotherapy or combination therapy. Individuals were censored at the time they discontinued their baseline diabetes treatment (metformin or sulfonylurea monotherapy) or received a prescription for a diabetes medication other than their baseline treatment.

\section{Outcome Measure}

The primary outcome was all-cause mortality. Mortality status was ascertained for the period from January 1, 2004, to December 31, 2009, using VA Vital Status files. These files have been shown to be accurate compared to the National Death Index. $^{19}$

\section{Statistical Analysis}

Primary Analysis. Mortality incidence rates and 95\% confidence intervals (CIs) were estimated for each treatment group by eGFR category. Unadjusted relative risk for metformin use compared with sulfonylurea use was 
estimated from these incidence rates. For the primary analysis, we used Cox regression to estimate hazard ratios (HRs) for mortality associated with initiation of metformin versus sulfonylurea monotherapy. The proportional hazards assumption was examined by visually inspecting $\log -\log$ plots, which were parallel and thus did not violate the assumption. Individuals were censored at the first occurrence of any of the following events: death, discontinuation of initial monotherapy, initiation of any other diabetes medication, or end of study on December 31, 2009. We selected covariates for adjustment a priori to reduce measured confounding by factors that might be associated with both mortality and the initial choice in prescribing metformin or sulfonylurea monotherapy. We adjusted for the following groups of covariates: demographic variables, health behaviors, eGFR category, comorbid conditions, laboratory values, and cardiovascular medication use. The VA is divided into 21 geographic areas, called Veterans Integrated Service Networks (VISN), which we adjusted for. Multiple imputation was conducted for those missing HDL, LDL, or A1c values (missingness: $8 \%, 12 \%$, and $12 \%$, respectively) with 50 replications of the analytical data set. ${ }^{20}$ An interaction term was estimated for each treatment-by-eGFR category compared with the eGFR category $\geq 90 \mathrm{~mL} / \mathrm{min} / 1.73 \mathrm{~m}^{2}$.

Sensitivity analyses were conducted to assess the robustness of the primary analysis. First, complete adherence to initial monotherapy was assumed regardless of failure to refill the medication after cohort entry or the addition of a second glucose-lowering medication; this is similar to an intention-totreat analysis of a clinical trial. ${ }^{21}$ Second, a complete-case analysis was conducted by excluding those with missing data on HDL, LDL, or A1c values.

Secondary Analyses. Cox regression was used to estimate HRs for mortality associated with initiation of metformin versus sulfonylurea monotherapy among various subgroups (age $<65$ vs. $\geq 65$ years; age $<75$ vs. $\geq 75$ years; $\mathrm{BMI}<30$ vs. $\geq 30$; previous cardiovascular disease; and previous congestive heart failure) within each eGFR category, with adjustment for the same variables as in the primary analyses and using multiple imputation to handle missing HDL, LDL, or A1c values. Interaction terms were estimated for each subgroup between treatment and eGFR categories. To evaluate absolute differences in mortality rates associated with metformin versus sulfonylurea monotherapy, we estimated adjusted incidence rates for mortality by treatment group and eGFR category using Poisson regression. We then calculated adjusted risk differences, comparing individuals receiving metformin with those receiving a sulfonylurea, and used a bootstrap analysis of 100 samples to estimate $95 \% \mathrm{CIs}^{22}$ Unadjusted KaplanMeier curves were generated by eGFR category. All statistical analyses were conducted with Stata (version 15.0; StataCorp LLC, College Station, TX, USA).

\section{RESULTS}

\section{Characteristics of the Study Population}

Of the 769,126 subjects who received a prescription for an oral glucose-lowering medication from January 1, 2004, to December 31, 2009, 175,296 initiators of metformin or sulfonylurea monotherapy met eligibility criteria for the cohort study (Fig. 1). Characteristics of participants at the time of cohort entry are shown in Table 1. Metformin initiators were on average younger, had a higher BMI, and had a lower prevalence of cardiovascular disease than sulfonylurea initiators. In addition, metformin initiators had higher eGFRs and slightly lower A1c values than sulfonylurea initiators.

\section{Glucose-Lowering Medication Use}

In $2004,33,685$ individuals initiated metformin $(52.4 \%)$ or sulfonylurea (47.6\%) monotherapy (Appendix Table 5). The proportion of metformin initiators increased during each year of the study, reaching $74.9 \%$ in 2009 . The average duration of initial monotherapy among metformin and sulfonylurea initiators was 1.7 years for both groups (Table 2). A similar proportion of metformin and sulfonylurea initiators used a second glucose-lowering medication during follow-up (22.6 and $28.8 \%$, respectively).

\section{Primary Analyses}

Unadjusted mortality rates were substantially lower for metformin initiators than for sulfonylurea initiators across all categories of eGFR (Appendix Table 6). In the primary analysis, adjusted for all measured potential confounding factors, metformin monotherapy initiation was associated with a significantly lower risk of mortality than sulfonylurea monotherapy initiation among the overall study population (HR 0.64, 95\% CI 0.60-0.68; Table 3). Metformin use was associated with lower mortality in all eGFR categories, and the 95\% CIs excluded a HR of 1 for all eGFR categories except $30-44 \mathrm{~mL} / \mathrm{min} / 1.73 \mathrm{~m}^{2}$. There was strong statistical evidence for an overall interaction between treatment group and eGFR category $(p=0.003)$, and the lowest mortality risk associated with metformin was observed in the highest eGFR category $(\geq 90 \mathrm{~mL} / \mathrm{min} /$ $1.73 \mathrm{~m}^{2}$ ). Among individuals with eGFR of $45-59 \mathrm{~mL} /$ $\min / 1.73 \mathrm{~m}^{2}$, the HR was of diminished magnitude but still significantly associated with lower mortality risk (HR 0.80, 95\% CI, 0.71-0.91; interaction $p<0.001)$. In sensitivity analyses using intention-to-treat and complete-case approaches, the magnitudes of the HRs within each eGFR category were similar to those from the primary analysis, but the statistical evidence for interaction by eGFR category was weaker (Appendix Table 7).

\section{Secondary Analyses}

The differences between mortality rates for metformin initiators and sulfonylurea initiators were similar in eGFR 
VA patients who received a prescription for diabetes treatment between January 1, 2004 and December 31, 2009 $(\mathrm{N}=769,126)$

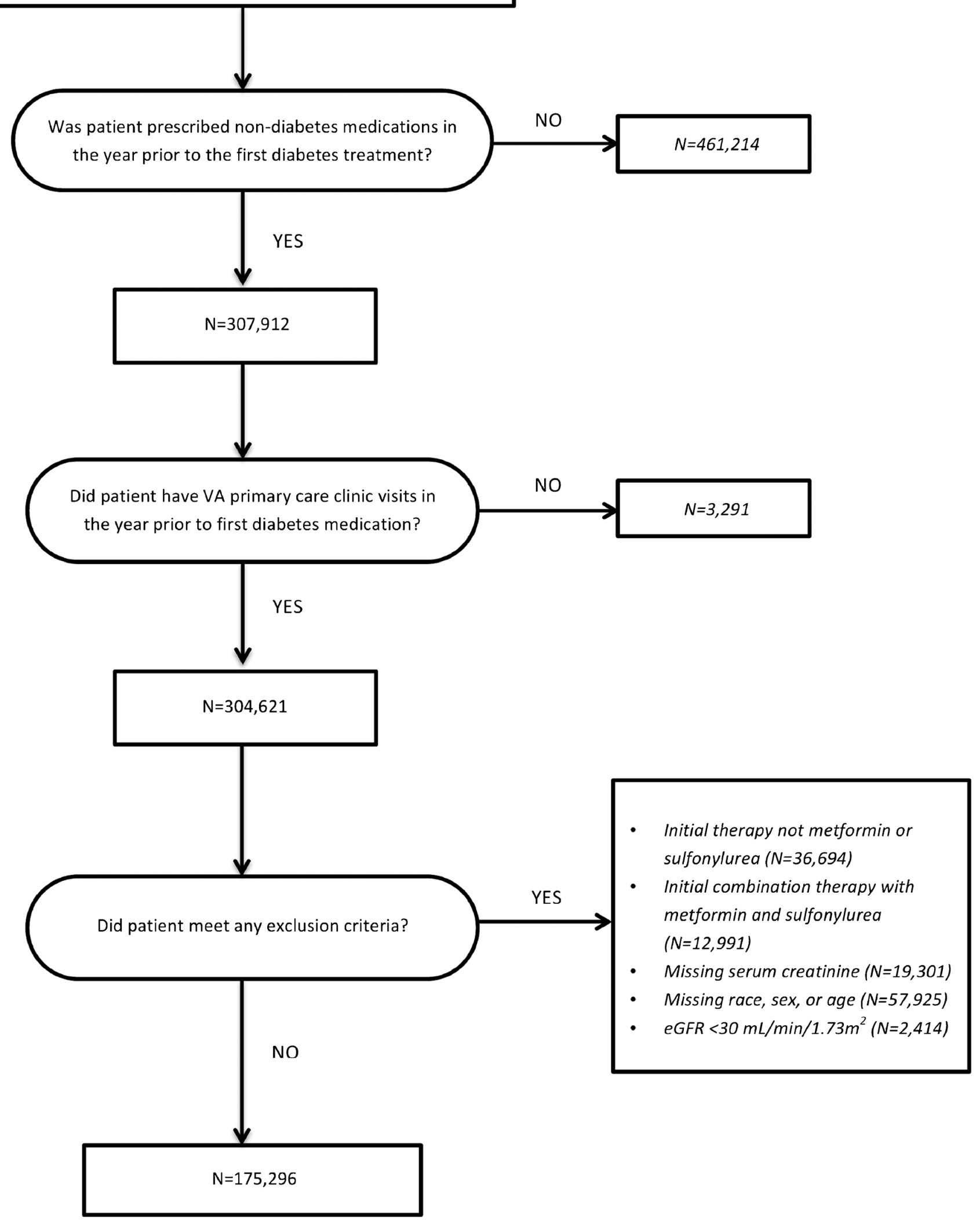

Figure 1 Eligibility criteria and sample size. 
Table 1 Baseline Characteristics of 175,296 Veterans Who Initiated Monotherapy with Metformin or a Sulfonylurea, Veterans Health Administration, 2004-2009

\begin{tabular}{|c|c|c|}
\hline & \multirow{2}{*}{$\begin{array}{l}\text { Metformin } \\
N=111,781\end{array}$} & \multirow{2}{*}{$\begin{array}{l}\text { Sulfonylurea } \\
N=63,515\end{array}$} \\
\hline & & \\
\hline \multicolumn{3}{|l|}{ Demographics, $n(\%)$} \\
\hline Mean age, years (SD) & $64.1(10.3)$ & $67.8(11.2)$ \\
\hline Male & $\begin{array}{l}107,645 \\
(96.3)\end{array}$ & $62,192(97.9)$ \\
\hline Race & & - \\
\hline White & $92,986(83.2)$ & $51,862(81.6)$ \\
\hline Black & $14,607(13.1)$ & $9453(14.9)$ \\
\hline Other & $4188(3.7)$ & $2200(3.5)$ \\
\hline \multicolumn{3}{|l|}{ Health behavior, $n(\%)$} \\
\hline BMI & - & - \\
\hline$<25$ & $8246(7.5)$ & 7434 (11.9) \\
\hline $25-29.9$ & $32,623(29.6)$ & $21,725(34.8)$ \\
\hline $30-34.9$ & $36,888(33.5)$ & $19,522(31.3)$ \\
\hline $35-39.9$ & $20,133(18.3)$ & $8958(14.4)$ \\
\hline $40+$ & $12,330(11.2)$ & $4738(7.6)$ \\
\hline Tobacco use diagnosis & $28,723(25.7)$ & $14,655(23.1)$ \\
\hline Alcohol diagnosis & $4265(3.8)$ & $2300(3.6)$ \\
\hline \multicolumn{3}{|c|}{ Estimated glomerular filtration rate (eGFR), $n(\%)$} \\
\hline Mean eGFR, $\mathrm{mL} / \mathrm{min} / 1.73 \mathrm{~m}^{2}(\mathrm{SD})$ & $78.4(16.6)$ & $68.1(20.7)$ \\
\hline eGFR category $\left(\mathrm{mL} / \mathrm{min} / 1.73 \mathrm{~m}^{2}\right)$ & - & - \\
\hline$\geq 90$ & $28,667(25.7)$ & $10,797(17.0)$ \\
\hline$\overline{60}-89$ & $67,541(60.4)$ & $27,948(44.0)$ \\
\hline $45-59$ & 14,407 (12.9) & $15,635(24.6)$ \\
\hline $30-44$ & $1166(1.0)$ & $9135(14.4)$ \\
\hline \multicolumn{3}{|l|}{ Comorbid conditions*, $n(\%)$} \\
\hline Hypertension & $85,891(76.8)$ & 49,293 (77.6) \\
\hline Hyperlipidemia & $68,405(61.2)$ & $35,581(56.0)$ \\
\hline Acute myocardial infarction & $299(0.3)$ & $222(0.4)$ \\
\hline Myocardial infarction & $2485(2.2)$ & $1842(2.9)$ \\
\hline Stable angina & $19,864(17.8)$ & $14,751(23.2)$ \\
\hline Other coronary artery disease & $14,457(12.9)$ & $9868(15.5)$ \\
\hline Congestive heart failure & $4801(4.3)$ & $6219(9.8)$ \\
\hline Peripheral vascular disease & $6628(5.9)$ & $5360(8.4)$ \\
\hline Cerebrovascular disease & $6780(6.1)$ & $5124(8.1)$ \\
\hline Neuropathy & $1883(1.7)$ & $1391(2.2)$ \\
\hline Retinopathy & 1833 (1.6) & $1551(2.4)$ \\
\hline Diabetic foot ulcer & $499(0.5)$ & $377(0.6)$ \\
\hline \multicolumn{3}{|l|}{ Laboratory results ${ }^{\dagger}$} \\
\hline $\begin{array}{l}\text { Mean HDL cholesterol, mg/dL } \\
\text { (SD) }\end{array}$ & $39.4(11.2)$ & $39.4(12.1)$ \\
\hline Mean LDL cholesterol, mg/dL & $99.2(35.6)$ & $97.0(36.0)$ \\
\hline (SD) & & \\
\hline Mean creatinine, mg/dL (SD) & $1.0(0.2)$ & $1.2(0.3)$ \\
\hline Mean hemoglobin A1c, \% (SD) & $7.2(2.9)$ & $7.4(2.9)$ \\
\hline \multicolumn{3}{|l|}{ Cardiovascular medications, $n(\%)$} \\
\hline Nitrates & $12,948(11.6)$ & $10,205(16.0)$ \\
\hline Thiazide diuretic & $26,601(23.8)$ & $14,187(22.3)$ \\
\hline Loop diuretic & $12,165(10.9)$ & $12,831(20.2)$ \\
\hline Potassium-sparing diuretic & $6300(5.6)$ & $5335(8.4)$ \\
\hline Calcium channel blocker & $27,832(24.9)$ & $17,974(28.3)$ \\
\hline Beta-blocker & $45,142(40.4)$ & $29,222(46.0)$ \\
\hline ACE inhibitor & $52,356(46.8)$ & $31,670(49.9)$ \\
\hline Angiotensin receptor blocker & $8470(7.6)$ & $4956(7.8)$ \\
\hline Cardiac glycosides & $4475(4.0)$ & $5467(8.6)$ \\
\hline Statin & $74,572(66.7)$ & $39,905(62.8)$ \\
\hline Fibrates & $11,326(10.1)$ & $6013(9.5)$ \\
\hline Aspirin & $18,032(16.1)$ & $10,741(16.9)$ \\
\hline Other antiplatelet & $7503(6.7)$ & $5624(8.9)$ \\
\hline Warfarin & $6958(6.2)$ & $6009(9.5)$ \\
\hline
\end{tabular}

*Comorbid conditions identified from the presence of ICD-9 diagnosis codes in medical encounters during the year prior to initiation of diabetes treatment (Appendix Table 4 for ICD-9 codes)

${ }^{\dagger} H D L$ cholesterol, LDL cholesterol, and hemoglobin Alc missing in 8\%, $12 \%$, and $12 \%$, respectively

categories $\geq 90 \mathrm{~mL} / \mathrm{min} / 1.73 \mathrm{~m}^{2}$ (3.0 fewer deaths $/ 1000$ person-years; $95 \% \mathrm{CI}, 1.5-4.4), 60-89 \mathrm{~mL} / \mathrm{min} / 1.73 \mathrm{~m}^{2}(4.3$ fewer deaths $/ 1000$ person-years; $95 \%$ CI, 3.2-5.4), and
Table 2 Glucose-Lowering Medication Use among Initiators of Metformin and Sulfonylurea Monotherapy, Veterans Health Administration, 2004-2009

\begin{tabular}{lll}
\hline \hline & $\begin{array}{l}\text { Metformin } \\
\text { monotherapy } \\
\mathbf{N = 1 1 1 , 7 8 1}\end{array}$ & $\begin{array}{l}\text { Sulfonylurea } \\
\text { monotherapy } \\
\mathbf{N = 6 3 , 5 1 5}\end{array}$ \\
\hline $\begin{array}{l}\text { Duration of initial monotherapy } \\
\text { treatment, mean years (SD) }\end{array}$ & $1.7(1.4)$ & $1.7(1.4)$ \\
$\begin{array}{l}\text { Duration of initial monotherapy } \\
\text { treatment, median years (IQR) }\end{array}$ & $1.3(0.6-2.5)$ & $1.3(0.6-2.5)$ \\
$\begin{array}{l}\text { Maximum duration of initial } \\
\text { monotherapy, years }\end{array}$ & 6.2 & 6.2 \\
$\begin{array}{l}\text { Subjects with second glucose- } \\
\text { lowering medication added*, } n(\%)\end{array}$ & $25,305(22.6)$ & $18,267(28.8)$ \\
$\begin{array}{l}\text { Type of second glucose-lowering } \\
\text { medication added, } n(\%)\end{array}$ & - & - \\
$\quad \begin{array}{l}\text { Glipizide } \\
\text { Glyburide }\end{array}$ & $11,531(45.6)$ & $1364(7.5)$ \\
$\begin{array}{l}\text { Insulin } \\
\text { Metformin }\end{array}$ & $8428(33.3)$ & $270(1.5)$ \\
$\begin{array}{l}\text { Other } \\
\text { Rosiglitazone }\end{array}$ & - & $3984(21.3)$ \\
\hline
\end{tabular}

* Patients for whom an additional glucose-lowering medication was started beyond the study-defined time interval of medication use were considered to have switched to monotherapy with a different medication and were not included in this table

$45-59 \mathrm{~mL} / \mathrm{min} / 1.73 \mathrm{~m}^{2}$ (3.4 fewer deaths $/ 1000$ person-years; 95\% CI 1.3-5.4; Table 3). In eGFR category 30-44 mL/ $\mathrm{min} / 1.73 \mathrm{~m}^{2}$, the rate difference was substantially greater (12.1 fewer deaths/1000 person-years; 95\% CI, 5.219.0).

Within each eGFR category, the HRs for metformin versus sulfonylurea treatment were similar across subgroups defined by age, BMI, presence of prior cardiovascular disease, and prior heart failure (Figure 2; Appendix Table 8). There was statistical evidence of an interaction by prior cardiovascular disease $(p=0.01)$; within eGFR categories $\geq 90,60-89$, and $45-59 \mathrm{~mL} / \mathrm{min} / 1.73 \mathrm{~m}^{2}$, HRs were higher among persons with prior cardiovascular disease than among those without prior cardiovascular disease. In addition, there was weak statistical evidence of an interaction by age (75 years threshold; $p=0.04$ ); within eGFR categories $60-89,45-59$, and 30 $44 \mathrm{~mL} / \mathrm{min} / 1.73 \mathrm{~m}^{2}$, the mortality HRs for the comparison of metformin with sulfonylurea treatment were higher among persons aged $\geq 75$ years than among those $<75$ years. Unadjusted Kaplan-Meier curves overall and by eGFR category showed results consistent with the primary analyses (Appendix Figures 4 and 5).

\section{DISCUSSION}

In this large national cohort of Veterans with type 2 diabetes and CKD who initiated glucose-lowering therapy, metformin monotherapy was associated with substantially lower mortality than monotherapy with a sulfonylurea. The absolute difference in mortality rates appeared greatest among patients with the most severe CKD (eGFR $30-44 \mathrm{~mL} / \mathrm{min} / 1.73 \mathrm{~m}^{2}$ ), who also suffered the highest overall burden of mortality. The primary results were robust to sensitivity analyses that 
Table 3 Association between Initiation of Metformin or Sulfonylurea Monotherapy and Mortality among Veterans by eGFR Category, Veterans Health Administration, 2004-2009

\begin{tabular}{llll}
\hline \hline Metformin vs. Sulfonylurea & HR $(\mathbf{9 5 \%} \mathbf{C I})^{*}$ & Interaction $\boldsymbol{P}$ value & Absolute mortality rate difference $\mathbf{9 5 \%}$ CI) \\
\hline Overall & $0.64(0.60-0.68)$ & - & $-4.8(-5.6,-4.0)$ \\
eGFR $\left(\mathrm{mL} / \mathrm{min} / 1.73 \mathrm{~m}^{2}\right)$ & - & - & - \\
$\geq 90$ & $0.59(0.50-0.70)$ & Reference & $-3.0(-4.4,-1.5)$ \\
$60-89$ & $0.65(0.60-0.71)$ & 0.07 & $-4.3(-5.4,-3.2)$ \\
$45-59$ & $0.80(0.71-0.91)$ & $<0.001$ & $-3.4(-5.4,-1.3)$ \\
$30-44$ & $0.72(0.51-1.01)$ & 0.20 & $-12.1(-19.0,-5.2)$ \\
- & - & & - \\
\hline
\end{tabular}

Abbreviations: CI, confidence interval; eGFR, estimated glomerular filtration rate; HR, hazard ratio

*Includes only monotherapy users who received a refill within the time frame compatible with $80 \%$ adherence, as described in the text. Adjusted for the baseline covariates listed in Table 1, as well as Veterans Integrated Service Network (VISN). For those missing HDL, LDL, or Alc values, multiple imputation $(n=50)$ was conducted

${ }^{\dagger}$ Per 1000 person-years. Complete-case analysis excluded subjects with missing data on HDL cholesterol, LDL cholesterol, or hemoglobin Alc. Adjusted for the baseline covariates listed in Table 1, as well as Veterans Integrated Service Network (VISN)

evaluated assumptions about medication use assessment during follow-up and missing data. Subgroup analyses did not identify strong effect modifiers of these associations, although there was some evidence that the health benefits associated with metformin in this population may be slightly reduced among those with pre-existing cardiovascular disease and those aged 75 years and older.

A recent systematic review of health outcomes related to metformin use in populations with type 2 diabetes and contraindications to treatment concluded that metformin use in patients with moderate CKD was associated with improvements in key clinical outcomes. This finding was based, in part, on results from two observational studies that reported mortality by CKD stage, but which were rated as having a moderate risk of bias. ${ }^{12}$ Ekstrom et al. conducted an

Treatment effect by eGFR category and Age group

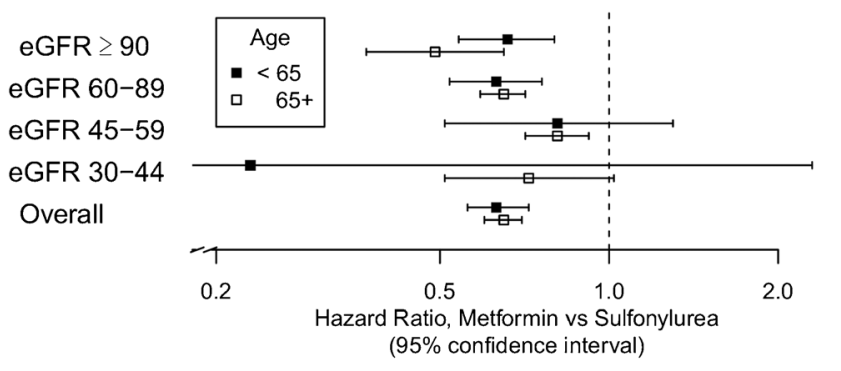

Treatment effect by eGFR category and CVD history

eGFR $\geq 90$ eGFR $60-89$ eGFR 45-59 eGFR 30-44 Overall

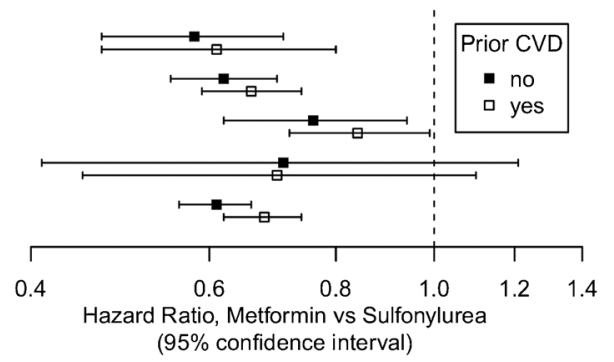

observational cohort study of 51,675 men and women with type 2 diabetes registered in the Swedish National Diabetes Register and regularly prescribed glucose-lowering treatment. ${ }^{7}$ They found that the use of metformin compared with any other glucose-lowering treatment was associated with a significantly reduced risk of mortality among 7177 patients with an eGFR of $45-59 \mathrm{~mL} / \mathrm{min} / 1.73 \mathrm{~m}^{2}$ (HR $0.87,95 \%$ CI 0.77-0.99), but not among 2146 patients with an eGFR of 30$44 \mathrm{~mL} / \mathrm{min} / 1.73 \mathrm{~m}^{2}$ (HR 1.02, 95\% CI 0.84-1.24). ${ }^{7}$ Roussel et al. conducted an observational study assessing whether metformin use was associated with a difference in mortality compared to non-metformin regimens in 19,691 patients with diabetes and advanced cardiovascular disease; among 4960 patients with an eGFR of $30-60 \mathrm{~mL} / \mathrm{min} / 1.73 \mathrm{~m}^{2}$, metformin use compared with non-use was associated with a reduced risk
eGFR $\geq 90$

eGFR $60-89$

eGFR 45-59

eGFR $30-44$

Overall

$\mathrm{eGFR} \geq 90$

eGFR $60-89$

eGFR 45-59

eGFR 30-44

Overall
Treatment effect by eGFR category and BMI group

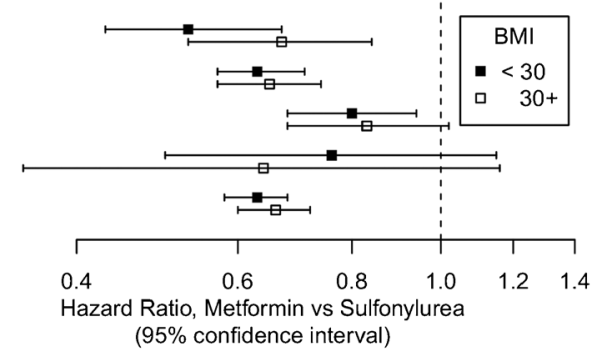

Treatment effect by eGFR category and CHF history

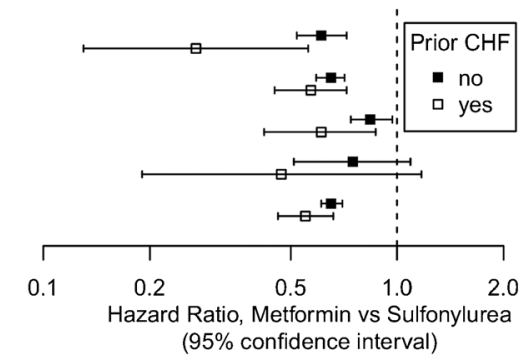

Figure 2 Association between initiation of metformin or sulfonylurea monotherapy and mortality among Veterans by eGFR category in subgroups, Veterans Health Administration, 2004-2009. Abbreviations: BMI, body mass index; CHF, congestive heart failure; CVD, cardiovascular disease; eGFR, estimated glomerular filtration rate. Adjusted for the baseline covariates listed in Table 1. 
of death (HR 0.64, 95\% CI 0.48-0.86). ${ }^{10}$ These studies had important methodological limitations: both lacked a welldefined comparator treatment group, and the study by Roussel evaluated prevalent rather than new users of metformin. In contrast, our study employed a new-user design and compared metformin initiators with sulfonylurea initiators in a large unselected population with type 2 diabetes and CKD, and we found that the use of metformin versus a sulfonylurea was associated with mortality benefits among all strata of eGFR evaluated, including persons with eGFR of $30-$ $44 \mathrm{~mL} / \mathrm{min} / 1.73 \mathrm{~m}^{2}$.

In the absence of clinical trial data evaluating the safety and effectiveness of metformin specifically in $\mathrm{CKD}$, regulatory bodies, professional societies, and clinicians must rely on well-conducted observational studies and meta-analyses. ${ }^{2}$ Our study provides evidence in support of the initiation of metformin treatment for type 2 diabetes among persons with an eGFR of $45 \mathrm{~mL} / \mathrm{min} / 1.73 \mathrm{~m}^{2}$ or greater, consistent with recent recommendations from the FDA and other experts. ${ }^{2,4}$ Moreover, our study provides new evidence that initiating metformin treatment may be beneficial among persons with an eGFR of $30-44 \mathrm{~mL} / \mathrm{min} / 1.73 \mathrm{~m}^{2}$, a group in whom initiation of metformin therapy is not currently recommended. ${ }^{4}$ If our findings are replicated in independent populations, the recommendation to restrict metformin treatment among persons with moderately-severely reduced eGFR may require reexamination.

Several biological mechanisms have been proposed by which metformin might reduce mortality: decreasing insulin and IGF-1 signaling, mTOR inhibition, reducing levels of reactive oxygen species, lowering inflammation, reducing DNA damage, and activating AMP-activated protein kinase (AMPK). ${ }^{23}$ Metformin has been described as a caloric restriction mimetic based partly on its effect on AMPK, and this drug is now being studied to examine its potential anti-aging effects. A systematic review reported that patients with diabetes taking metformin had significantly lower mortality and a lower risk of cardiovascular disease than patients taking nonmetformin therapies. ${ }^{23}$ If one of the pathways through which metformin reduces mortality is in decreasing the incidence or progression of atherosclerotic cardiovascular disease, then a reduced effect among persons with pre-existing cardiovascular disease would be expected. Our findings from subgroup analyses are consistent with this reasoning.

Our study has important strengths. First, this is the largest study of the use of metformin versus sulfonylureas in patients with type 2 diabetes and CKD. With 175,296 Veterans in the overall sample, we were able to achieve a sample size sufficient to evaluate metformin effects within narrow categories of eGFR. Second, the new-user design minimizes the confounding and selection biases that arise from evaluating prevalent users, which represent a heterogeneous cross-section of patients with varying severity and duration of diabetes, and may be depleted of persons who experienced early adverse effects or treatment failures. ${ }^{24}$ Third, we used rich VHA electronic health data to assess and adjust for important potential confounding factors. Fourth, in contrast to prior studies, we used a clinically meaningful direct comparison of metformin to a single glucose-lowering drug category (i.e., sulfonylureas), which reflects a well-defined clinical decision. Finally, glucose-lowering therapy use was assessed over time so that we were able to censor persons who became non-adherent to their initial treatment group.

Our study also has limitations. First, we did not have dosage information to assess a potential dose-response association. Second, since the period when this study was conducted, several new classes of glucose-lowering drugs have been approved, ${ }^{25}$ and large post-marketing randomized controlled trials suggest that some of these newer therapies may prevent cardiovascular complications. ${ }^{26}$ However, to evaluate the relative mortality risks associated with metformin versus a similarly used treatment, it was necessary to conduct these analyses during a time when there was greater clinical equipoise about the initial selection of glucose-lowering treatment for type 2 diabetes, before the widespread adoption of the recommendation to start treatment for type 2 diabetes with metformin. This analysis would not have yielded credible results if more recent data had been used. Third, although we adjusted for multiple covariates associated with mortality and metformin use, we cannot exclude the possibility of residual confounding by indication, given the observational design of this research. Fourth, while we controlled for VISN as a measure of potential regional variation within the VA, we were not able to control for provider characteristics associated with prescribing metformin versus sulfonylureas. Fifth, we were unable to determine the specific causes of CKD. Type 2 diabetes is the leading cause of CKD in the US. ${ }^{27}$ However, our study assessed eGFR prior to the initiation of diabetes treatment and early in the course of diabetes; therefore, CKD in this cohort was most often from other causes. For example, approximately $77 \%$ of the cohort had hypertension, a major risk factor for CKD. Lastly, the study population consisted mostly of older male Veterans, so the results may not generalize to women or younger populations.

In conclusion, our study suggests that initiation of treatment for type 2 diabetes with metformin versus a sulfonylurea in individuals with $\mathrm{CKD}$ is associated with substantially lower mortality, in terms of both relative and absolute risk reductions. The lower mortality associated with metformin was observed even among individuals with moderately-severely reduced eGFR $\left(30-44 \mathrm{~mL} / \mathrm{min} / 1.73 \mathrm{~m}^{2}\right)$, a population in which evidence regarding the health benefits of metformin is limited. These findings, together with results from previous studies, support the FDA's guidance to consider metformin initiation among individuals with an eGFR of $45-59 \mathrm{~mL} / \mathrm{min} /$ $1.73 \mathrm{~m}^{2}$, and suggests that metformin initiation may be beneficial among persons with even more severe CKD. Given the number of glucose-lowering drugs available, further comparative effectiveness research is needed to guide prescribing practices, especially for high-risk patient populations. 
Corresponding Author: James S. Floyd, MD, MS; Department of Medicine, Cardiovascular Health Research Unit, University of Washington, 1730 Minor Ave, Suite 1360, Seattle, WA 98101 USA (e-mail: jfloyd@uw.edu).

Funding Source Dr. Floyd received financial support from the National Heart, Lung, and Blood Institute (NHLBI grant K08HL116640). The views expressed by Drs. Boyko and Smith are theirs alone and do not necessarily represent the views of the Department of Veterans Affairs or the United States Government.

\section{Compliance with Ethical Standards:}

Conflict of Interest: All authors declare that they have no relevant financial interests, activities, relationships, or affiliations, or other potential conflicts of interest to report.

\section{REFERENCES}

1. American Diabetes Association. Standards of medical care in diabetes-2017: Summary of revisions. Diabetes Care. 2017;40:S4-5.

2. Inzucchi SE, Lipska KJ, Mayo H, Bailey CJ, McGuire DK. Metformin in patients with type 2 diabetes and kidney disease: a systematic review. JAMA. 2014;312:2668-75.

3. Flory JH, Hennessy S. Metformin use reduction in mild to moderate renal impairment: possible inappropriate curbing of use based on Food and Drug Administration contraindications. JAMA Intern Med. 2015; 175:458-9.

4. U.S. Food \& Drug Administration. FDA Drug Safety Communication: FDA revises warnings regarding use of the diabetes medicine metformin in certain patients with reduced kidney function. http://www.fda.gov/ Drugs/DrugSafety/ucm493244.htm. Accessed May 15, 2017.

5. Afkarian M, Zelnick LR, Hall YN, et al. Clinical manifestations of kidney disease among US adults with diabetes, 1988-2014. JAMA. 2016;316:602-10

6. Aguilar D, Chan W, Bozkurt B, Ramasubbu K, Deswal A. Metformin use and mortality in ambulatory patients with diabetes and heart failure. Circ Heart Fail. 2011;4:53-8.

7. Ekström N, Schiöler L, Svensson AM, et al. Effectiveness and safety of metformin in 51675 patients with type 2 diabetes and different levels of renal function: a cohort study from the Swedish National Diabetes Register. BMJ Open. 2012;2(4). https://doi.org/10.1136/bmjopen2012-001076.

8. Masoudi FA, Inzucchi SE, Wang Y, Havranek EP, Foody JM, Krumholz HM. Thiazolidinediones, metformin, and outcomes in older patients with diabetes and heart failure: an observational study. Circulation. 2005; 111:583-90.

9. Morgan CL, Mukherjee J, Jenkins-Jones S, Holden SE, Currie CJ. Association between first-line monotherapy with sulfonylurea versus metformin and risk of all-cause mortality and cardiovascular events: a retrospective, observational study. Diabetes Obes Metab. 2014;16:957-62.
10. Roussel R, Travert F, Pasquet B, et al. Metformin use and mortality among patients with diabetes and atherothrombosis. Arch Intern Med. 2010;170:1892-9.

11. Weir MA, Gomes T, Mamdani M, et al. Impaired renal function modifies the risk of severe hypoglycemia among users of insulin but not glyburide: a population-based nested case-control study. Nephrol Dial Transplant. 2011;26:1888-94.

12. Crowley MJ, Diamantidis CJ, McDuffie JR, et al. Clinical outcomes of metformin use in populations with chronic kidney disease, congestive heart failure, or chronic liver disease: a systematic review. Ann Intern Med. 2017;166:191-200

13. Hampp C, Borders-Hemphill V, Money DG, Wysowski DK. Use of antidiabetic drugs in the U.S., 2003-2012. Diabetes Care. 2014;37:1367-74.

14. American Diabetes Association. Standards of medical care for patients with diabetes mellitus. Diabetes Care. 2003;26:S33-50.

15. Floyd JS, Blondon M, Moore KP, Boyko EJ, Smith NL. Validation of methods for assessing cardiovascular disease using electronic health data in a cohort of Veterans with diabetes. Pharmacoepidemiol Drug Saf. 2016;25:467-71.

16. Wheeler S, Moore $\mathbf{K}$, Forsberg $\mathbf{C W}$, et al. Mortality among veterans with type 2 diabetes initiating metformin, sulfonylurea or rosiglitazone monotherapy. Diabetologia. 2013;56:1934-43.

17. Levey AS, Stevens LA, Schmid CH, et al. A new equation to estimate glomerular filtration rate. Ann Intern Med. 2009;150:604-12.

18. KDIGO 2012 Clinical Practice Guideline for the Evaluation and Management of Chronic Kidney Disease. Chapter 2: definition, identification, and prediction of CKD progression. Kidney Int Suppl. 2013;3:63-72; https:// doi.org/10.1038/kisup.2012.65

19. Cowper DC, Kubal JD, Maynard C, Hynes DM. A primer and comparative review of major US mortality databases. Ann Epidemiol. 2002:12:462-8.

20. Schafer JL. Analysis of Incomplete Multivariate Data. Boca Raton, FL: Chapman \& Hall/CRC; 1997.

21. Danaei G, Rodriguez LA, Cantero OF, Logan R, Hernán MA. Observational data for comparative effectiveness research: an emulation of randomised trials of statins and primary prevention of coronary heart disease. Stat Methods Med Res. 2013;22:70-96.

22. Bansal N, Katz R, Robinson-Cohen $\mathbf{C}$, et al. Absolute rates of heart failure, coronary heart disease, and stroke in chronic kidney disease: an analysis of 3 community-based cohort studies. JAMA Cardiol. 2017;2:314-8.

23. Campbell JM, Bellman SM, Stephenson MD, Lisy K. Metformin reduces all-cause mortality and disease of ageing independent of its effect on diabetes control: A systematic review and meta-analysis. Ageing Res Rev. 2017;40:31-44.

24. Ray WA, Meredith S, Thapa PB, Meador KG, Hall K, Murray KT. Antipsychotics and the risk of sudden cardiac death. Arch Gen Psychiatry. 2001;58:1161-7.

25. Flory JH, Ukena JK, Floyd JS. Novel anti-glycemic drugs and reduction of cardiovascular risk in diabetes: expectations realized, promises unmet. Curr Atheroscler Rep. 2016;18:79.

26. Smith RJ, Goldfine AB, Hiatt WR. Evaluating the cardiovascular safety of new medications for type 2 diabetes: time to reassess? Diabetes Care. 2016;39:738-42.

27. Koro CE, Lee BH, Bowlin SJ. Antidiabetic medication use and prevalence of chronic kidney disease among patients with type 2 diabetes mellitus in the United States. Clin Ther. 2009;31:2608-17.

\section{APPENDIX}

Before starting metformin, obtain the patient's eGFR

Metformin is contraindicated in patients with an eGFR below $30 \mathrm{~mL} /$ minute $/ 1.73 \mathrm{~m}^{2}$

Starting metformin in patients with an eGFR between $30-45 \mathrm{~mL} /$ minute $/ 1.73 \mathrm{~m}^{2}$ is not recommended

$\square \quad$ Obtain an eGFR at least annually in all patients taking metformin. In patients at an increased risk for the development of renal impairment such as the elderly, renal function should be assessed more frequently.

$\square \quad$ In patients taking metformin whose eGFR later falls below $45 \mathrm{~mL} /$ minute $/ 1.73 \mathrm{~m}^{2}$, assess the benefits and risks of continuing treatment. Discontinue metformin if the patient's eGFR later falls below $30 \mathrm{~mL} /$ minute $/ 1.73 \mathrm{~m}^{2}$

Figure 3 FDA labeling updates for metformin-containing products, April 2016. 


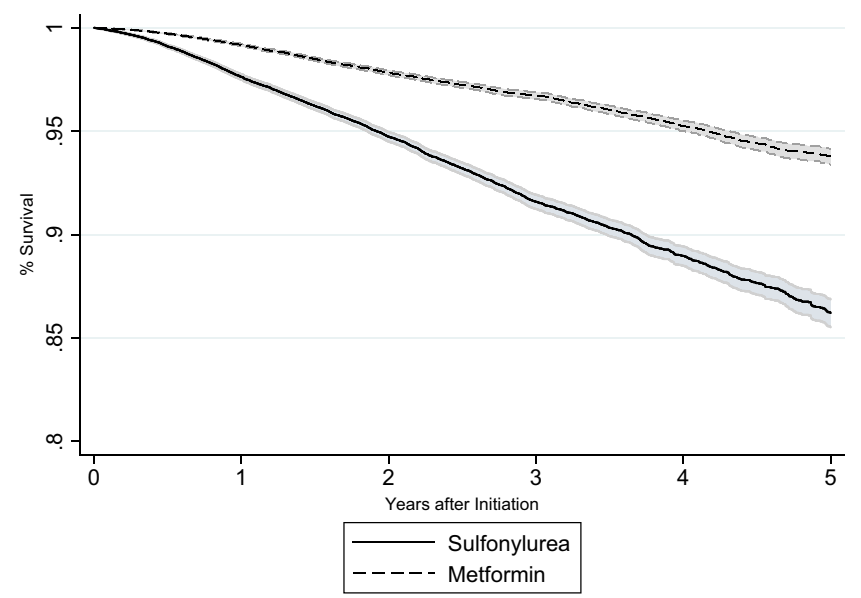

Figure 4 Kaplan-Meier curves for survival among metformin and sulfonylurea monotherapy users, unadjusted.
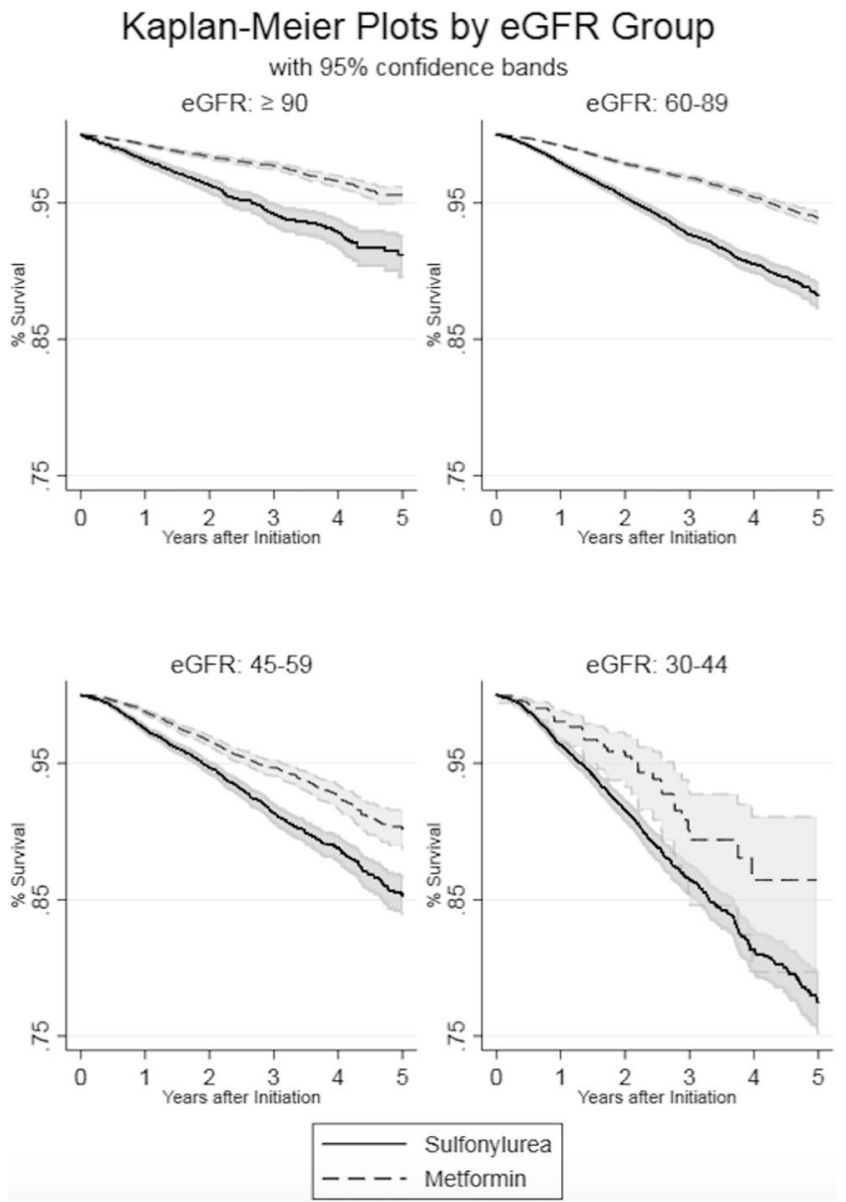

Figure 5 Kaplan-Meier curves for survival among metformin and sulfonylurea monotherapy users by eGFR category, unadjusted. 
Table 4 ICD-9 Codes for Comorbid Conditions

\begin{tabular}{lc}
\hline$\overline{\text { Comorbid conditions }}$ & \multicolumn{1}{c}{$401.0,401.1,401.9$} \\
\hline Hypertension & $272.2,272.4$ \\
Hyperlipidemia & $410 . x x$ \\
Acute myocardial infarction & $411.0,412$ \\
Myocardial infarction & $411.8 \times, 413.9,414.0 \times, 414.2,414.3$ \\
Stable angina & $414.8,414.9$ \\
Other coronary artery disease & $428,402 . x$ \\
Congestive heart failure & $440,441,442,443,444,445$ \\
Peripheral vascular disease & $431,433,434,435,436,437,438$ \\
Cerebrovascular disease & \\
Neuropathy & $250.60,250.62$ \\
Retinopathy & $250.50,362.10,362.0 \times$ \\
Diabetic foot ulcer & 250.80 \\
\hline
\end{tabular}

Table 5 Initiation of Metformin and Sulfonylurea Monotherapy by Calendar Year, Veterans Health Administration, 2004-2009

\begin{tabular}{llllllll}
\hline \hline No. (\%) & $\mathbf{2 0 0 4}$ & $\mathbf{2 0 0 5}$ & $\mathbf{2 0 0 6}$ & $\mathbf{2 0 0 7}$ & $\mathbf{2 0 0 8}$ & $\mathbf{2 0 0 9}$ \\
\hline Metformin & 17,657 & 19,797 & 20,676 & 19,802 & 19,044 & 14,805 \\
Sulfonylurea & $(52.4)$ & $(58.1)$ & $(63.1)$ & $(68.5)$ & $(73.0)$ & $(74.9)$ & 111,781 \\
& 16,028 & 14,302 & 12,065 & 9112 & 7053 & 4955 \\
Total & $(47.6)$ & $(41.9)$ & $(36.9)$ & $(31.5)$ & $(27.0)$ & $(25.1)$ & 63,515 \\
\hline
\end{tabular}

Table 6 Unadjusted Mortality Rates among Initiators of Metformin or Sulfonylurea Monotherapy, Veterans Health Administration, 20042009

\begin{tabular}{|c|c|c|c|c|c|c|c|c|c|}
\hline $\begin{array}{l}\text { eGFR } \\
(\mathrm{mL} / \mathrm{min} / \\
\left.1.73 \mathrm{~m}^{2}\right)\end{array}$ & $\begin{array}{l}\text { MET } \\
\text { users, } \\
n\end{array}$ & $\begin{array}{l}\text { SU } \\
\text { users, } \\
n\end{array}$ & $\begin{array}{l}\text { MET } \\
\text { deaths, } \\
n\end{array}$ & $\begin{array}{l}\text { SU } \\
\text { deaths, } \\
n\end{array}$ & $\begin{array}{l}\text { MET total } \\
\text { person- } \\
\text { years }\end{array}$ & $\begin{array}{l}\text { SU total } \\
\text { person- } \\
\text { years }\end{array}$ & $\begin{array}{l}\text { MET incidence } \\
\text { rate* } \\
(\mathbf{9 5 \%} \text { CI) }\end{array}$ & $\begin{array}{l}\text { SU incidence } \\
\text { Rate* } \\
(95 \% \text { CI) }\end{array}$ & $\begin{array}{l}\text { Relative risk } \\
\text { (MET vs. SU) } \\
\text { (95\% CI) }\end{array}$ \\
\hline Overall & 111,781 & 63,515 & 2123 & 2998 & 194,509 & 109,455 & $10.9(10.5-11.4)$ & $27.4(27.4-28.4)$ & $0.40(0.38-0.42)$ \\
\hline $60-89$ & 67,541 & 27,948 & 1288 & 1156 & 121,951 & 49,003 & $10.6(10.0-11.1)$ & $23.6(22.3-25.0)$ & $0.45(0.41-0.49)$ \\
\hline $45-59$ & 14,407 & 15,635 & 426 & 811 & 24.862 & 28,602 & $17.1(15.6-18.8)$ & $28.4(26.5-30.4)$ & $0.60(0.54-0.68)$ \\
\hline $30-44$ & 1166 & 9135 & 38 & 734 & 1540 & 16,162 & 24.7 (17.9-33.9) & $45.4(42.2-48.8)$ & $0.54(0.38-0.75)$ \\
\hline
\end{tabular}

Abbreviations: CI, confidence interval, eGFR, estimated glomerular filtration rate; MET, metformin; SU, sulfonylurea

*Per 1000 person-years

Table 7 Association between Initiation of Metformin or Sulfonylurea Monotherapy and Mortality among Veterans by eGFR Category, Veterans Health Administration, 2004-2009

\begin{tabular}{|c|c|c|c|c|}
\hline & \multicolumn{2}{|l|}{ Intention-to-treat* } & \multicolumn{2}{|l|}{ Complete-case $^{\dagger}$} \\
\hline & HR $(95 \%$ CI) & Interaction $P$ value & HR $(95 \% \mathrm{CI})^{*}$ & Interaction $P$ value \\
\hline \multirow{7}{*}{$\begin{array}{l}\text { Metformin vs. sulfonylurea } \\
\text { eGFR }\left(\mathrm{mL} / \mathrm{min} / 1.73 \mathrm{~m}^{2}\right) \\
\geq 90 \\
60-89 \\
45-59 \\
30-44\end{array}$} & $0.65(0.62-0.69)$ & - & $0.68(0.63-0.73)$ & - \\
\hline & - & - & & \\
\hline & $0.65(0.55-0.76)$ & Reference & $0.74(0.60-0.90)$ & Reference \\
\hline & $0.66(0.60-0.71)$ & 0.34 & $0.67(0.61-0.74)$ & 0.73 \\
\hline & $0.79(0.70-0.89)$ & 0.01 & $0.82(0.71-0.95)$ & 0.23 \\
\hline & $0.75(0.54-1.04)$ & 0.31 & $0.75(0.49-1.15)$ & 0.83 \\
\hline & & 0.04 (overall) & & 0.20 (Overall) \\
\hline
\end{tabular}

*Intention-to-treat analysis did not censor subjects based on discontinuation of the initial monotherapy treatment or the addition of a second therapy ${ }^{\dagger}$ Complete-case analyses excluded subjects with missing data on HDL cholesterol, LDL cholesterol, or hemoglobin Alc

${ }^{*}$ Includes only monotherapy users who received a refill within the time frame compatible with $80 \%$ adherence, as described in the text. Adjusted for the baseline covariates listed in Table 1, as well as Veterans Integrated Service Network (VISN). For those missing HDL, LDL, or Alc values, multiple imputation $(n=50)$ was conducted 
Table 8 Association between Initiation of Metformin Versus Sulfonylurea Monotherapy and Mortality among Veterans by eGFR Category in Subgroups, Veterans Health Administration, 2004-2009

\begin{tabular}{|c|c|c|c|c|c|c|}
\hline & \multicolumn{6}{|c|}{ eGFR $\left(\mathrm{mL} / \mathrm{min} / 1.73 \mathrm{~m}^{2}\right)^{*}$} \\
\hline & $\begin{array}{l}\geq 90 \\
\text { HR }(95 \% \text { CI })\end{array}$ & $\begin{array}{l}\text { 60-89 } \\
\text { HR }(95 \% \text { CI })\end{array}$ & $\begin{array}{l}45-59 \\
\text { HR }(95 \% \text { CI })\end{array}$ & $\begin{array}{l}30-44 \\
\text { HR }(95 \% \text { CI })\end{array}$ & $\begin{array}{l}\text { Overall } \\
\text { HR }(95 \% \text { CI) }\end{array}$ & $\begin{array}{l}P \text { value for interaction } \\
\text { in overall sample }\end{array}$ \\
\hline \multicolumn{6}{|l|}{ Age } & \multirow[t]{3}{*}{0.35} \\
\hline$<65$ years & $0.66(0.54-0.80)$ & $0.63(0.52-0.76)$ & $0.81(0.51-1.30)$ & $0.23(0.02-2.30)$ & $0.63(0.56-0.72)$ & \\
\hline $65+$ years & $0.49(0.37-0.65)$ & $0.65(0.59-0.71)$ & $0.81(0.71-0.92)$ & $0.72(0.51-1.02)$ & $0.65(0.60-0.70)$ & \\
\hline \multicolumn{6}{|l|}{ Age } & \multirow[t]{3}{*}{0.04} \\
\hline$<75$ years & $0.60(0.51-0.71)$ & $0.63(0.56-0.71)$ & $0.79(0.63-0.98)$ & $0.34(0.12-0.93)$ & $0.61(0.56-0.67)$ & \\
\hline $75+$ years & $0.52(0.30-0.92)$ & $0.66(0.58-0.74)$ & $0.82(0.70-0.96)$ & $0.80(0.56-1.16)$ & $0.68(0.62-0.75)$ & \\
\hline \multicolumn{6}{|l|}{ BMI } & \multirow[t]{3}{*}{0.66} \\
\hline$<30$ & $0.53(0.43-0.67)$ & $0.63(0.57-0.71)$ & $0.80(0.68-0.94)$ & $0.76(0.50-1.15)$ & $0.63(0.58-0.68)$ & \\
\hline $30+$ & $0.67(0.53-0.84)$ & $0.65(0.57-0.74)$ & $0.83(0.68-1.02)$ & $0.64(0.35-1.16)$ & $0.66(0.60-0.72)$ & \\
\hline \multicolumn{6}{|l|}{ Previous CVD } & \multirow[t]{3}{*}{0.01} \\
\hline No & $0.58(0.47-0.71)$ & $0.62(0.55-0.70)$ & $0.76(0.62-0.94)$ & $0.71(0.41-1.21)$ & $0.61(0.56-0.66)$ & \\
\hline Yes & $0.61(0.47-0.80)$ & $0.66(0.59-0.74)$ & $0.84(0.72-0.99)$ & $0.70(0.45-1.10)$ & $0.68(0.62-0.74)$ & \\
\hline \multicolumn{6}{|l|}{ Previous CHF } & \multirow[t]{3}{*}{0.25} \\
\hline No & $0.61(0.52-0.72)$ & $0.65(0.59-0.71)$ & $0.84(0.74-0.97)$ & $0.75(0.51-1.09)$ & $0.65(0.61-0.70)$ & \\
\hline Yes & $0.27(0.13-0.56)$ & $0.57(0.45-0.72)$ & $0.61(0.42-0.87)$ & $0.47(0.19-1.17)$ & $0.55(0.46-0.66)$ & \\
\hline
\end{tabular}

Abbreviations: BMI, body mass index; CHF, congestive heart failure; CKD, chronic kidney disease; CVD, cardiovascular disease; eGFR, estimated glomerular filtration rate

*Adjusted for the baseline covariates listed in Table 1 